\title{
Potencial ornamental de acessos de pimenta
}

\author{
Potential for ornamental use of pepper accessions
}

\begin{abstract}
Leane Fialho de Melo ${ }^{I}$ Regina Lucia Ferreira Gomes ${ }^{I I}$ Verônica Brito da Silva ${ }^{I}$ Eliane Rodrigues Monteiro ${ }^{\mathrm{III}}$ Ângela Celis Almeida Lopes ${ }^{\mathrm{IV}}$ Ana Paula Peron ${ }^{\mathrm{V}}$
\end{abstract}

RESUMO

O objetivo deste trabalho foi avaliar o potencial ornamental de dez acessos de pimenta Capsicum spp. procedentes da Coleção de Germoplasma da Universidade Federal do Piauí, Brasil. $O$ experimento foi conduzido em casa de vegetação, no Departamento de Fitotecnia, do Centro de Ciências Agrárias, no município de Teresina, Piauí, obedecendo ao delineamento experimental inteiramente casualizado, com três repetições. $\mathrm{Na}$ caracterização morfoagronômica dos acessos, conforme orientação do Bioversity International, utilizaram-se os seguintes descritores qualitativos e quantitativos para o gênero Capsicum: forma da folha, hábito de crescimento da planta, antocianina no nó da planta, posição da flor, cor da corola, cor do fruto no estado intermediário e maduro, forma do fruto, forma do ápice do fruto, textura da epiderme do fruto, comprimento do fruto, comprimento do pedicelo, persistência do fruto maduro e altura da planta. Dentre os dez acessos avaliados, sete foram considerados com potencial ornamental: CGC-06 (C. chinense), CGC-07 (C. chinense), CGC-11 (C. annuum var. glabriusculum), CGC-23 (C. chinense), CGC-36 (C. annuum var. glabriusculum), $C G C$ 59 (C. annuum var. glabriusculum) e CGC-67 (C. annuum var. glabriusculum). O CGC 11 apresentou estética mais harmoniosa, com flores eretas, as quais são de fácil percepção; frutos eretos e vistosos e folhas de formato lanceolado.

Palavras-chave: Capsicum spp., descritores morfoagronômicos, coleção de germoplasma.

\section{ABSTRACT}

The objective of this research was to evaluate the potential for ornamental use of ten Capsicum spp. accessions from Germplasm Collection of Federal University of Piauí, Brazil The experiment was carried out in a greenhouse at the Department of Plant Science, Centre of Agricultural Sciences, in Teresina City, Piaui State, according to the completely randomized design, with three replications. In the morphoagronomic characterization of pepper accessions, according to Bioversity International, the following qualitative and quantitative descriptors for the Capsicum genus were used: leaf shape, plant growth habit, anthocyanin node of the plant, flower position, color of the corolla, fruit color and mature in the intermediate state, fruit shape, fruit shape of apex of the texture of the fruit skin, fruit length, length of pedicel, persistence of ripe fruit and plant height. Among the ten accessions, seven were considered with ornamental potential: CGC-06 (C. chinense), CGC-07 (C. chinense), CGC-11 (C. annuum var. glabriusculum), CGC-23 (C. chinense), CGC36 (C. annuum var. glabriusculum), CGC-59 (C. annuum var. glabriusculum) and CGC-67 (C. annuum var. glabriusculum). The CGC 11 was the more harmonious aesthetic accession, by presenting erect flowers, which are easy to read; erect and showy fruits and lanceolate leaves format.

Key words: Capsicum spp., morphoagronomic descriptors, germplasm collection.

\section{INTRODUÇÃO}

O agronegócio de flores e plantas ornamentais é um segmento de grande importância socioeconômica para o Brasil, por empregar direta e indiretamente mais de 120 mil pessoas em todo o país, produzir e comercializar anualmente 900 milhões de unidades de flores e plantas ornamentais

\footnotetext{
IPrograma de Pós-graduação em Genética e Melhoramento, Centro de Ciências Agrárias (CCA), Universidade Federal do Piauí (UFPI), Teresina, PI, Brasil.

IIDepartamento de Fitotecnia, CCA, UFPI, 64049-550, Teresina, PI, Brasil. E-mail: rlfgomes@ufpi.edu.br. Autor para correspondência.

IIIPrograma de Pós-graduação em Agronomia, CCA, UFPI, Teresina, PI, Brasil.

${ }^{\text {IV }}$ Departamento de Biologia, CCN, UFPI, Teresina, PI, Brasil.

${ }^{\vee}$ Campus Senador Helvídio Nunes de Barros, UFPI, Picos, PI, Brasil. 
(JUNQUEIRA \& PEETZ, 2011). Segundo RIBEIRO (2012), somente em 2011 foram comercializadas 47 mil toneladas de flores e plantas em vaso, sendo Minas Gerais, Rio de Janeiro e São Paulo os principais estados produtores e exportadores.

As pimentas do gênero Capsicum spp. se destacam como um importante segmento do mercado de hortaliças frescas no Brasil, com ênfase nas espécies $\boldsymbol{C}$. annum L. (pimentão), $\boldsymbol{C}$. chinense Jaqc. (pimenta-de-cheiro), $\boldsymbol{C}$. frutencens L. (pimenta malagueta) e $\boldsymbol{C}$. baccatum L. (dedo-de-moça), que são muito consumidas e produzidas, de excelente adaptação às condições de clima tropical e com ampla variabilidade genética (ZENI \& BOSIO, 2011). Em função desta variabilidade, algumas variedades de pimentas possuem características de grande valor estético para a ornamentação, como folhas variegadas, porte anão e frutos de cores intensas, que contrastam com a folhagem, apresentando diferentes colorações antes e após a maturação (CARVALHO et al., 2006). Além disso, também são de fácil cultivo, de grande durabilidade e com ampla capacidade de crescer em recipientes como planta perene (NEITZKE et al., 2010).

No entanto, embora o Brasil seja considerado um habitat natural para o cultivo destas plantas, ainda são poucas as variedades comerciais destinadas a ornamentação (VASCONCELOS et al., 2012). Assim, de acordo com DOMENICO et al. (2012), torna-se relevante avaliar o potencial ornamental de acessos de pimenta presentes em bancos de germoplasmas, com o intuito de gerar maior número de dados sobre o material conservado, e disponibilizar tais informações para estimular a sua utilização de forma mais efetiva no setor da floricultura, bem como auxiliar futuros programas de melhoramento genético na criação de novas cultivares de pimentas ornamentais.
Nesse contexto, o presente trabalho teve por objetivo avaliar o potencial ornamental de dez acessos de pimentas Capsicum spp., procedentes da Coleção de Germoplasma da Universidade Federal do Piauí, com base em descritores morfoagronômicos qualitativos e quantitativos referenciados na literatura científica como os mais relevantes para a caracterização ornamental.

\section{MATERIAIS E MÉTODOS}

O estudo foi desenvolvido no período de agosto de 2007 a julho de 2008, no Departamento de Fitotecnia, do Centro de Ciências Agrárias (CCA), da Universidade Federal do Piauí (UFPI), no município de Teresina, Piauí, situado a $05^{\circ} 05^{\prime} \mathrm{S}$ de latitude, $42^{\circ} 05^{\prime} \mathrm{W}$ de longitude e $72,70 \mathrm{~m}$ de altitude, cujo clima é do tipo AS', pela classificação de Köppen.

Na realização deste trabalho, utilizaram-se dez acessos de Capsicum spp. procedentes da Coleção de Germoplasma da UFPI (Tabela 1), que foram selecionados por apresentarem frutos com cores e formas variadas, acima da folhagem. $\mathrm{O}$ código dos acessos foi designado pela sigla CGC, que significa Coleção de Germoplasma de Capsicum, seguida de um número referente à ordem de registro da entrada do material na coleção. Para identificação botânica desses acessos, foram preparadas exsicatas, com dois exemplares floridos (ramos férteis) de cada acesso, para posterior incorporação no Herbário Graziela Barroso (TEPB), localizado no Núcleo de Referência em Ciências Ambientais do Trópico Ecotonal do Nordeste (TROPEN) da UFPI.

O experimento foi instalado em casa de vegetação, obedecendo ao delineamento experimental inteiramente casualizado, com dez tratamentos (acessos) e três repetições, sendo uma planta por vaso. Cada parcela foi constituída por quatro plantas.

Tabela 1 - Acessos de Capsicum spp. da Coleção de Germoplasma da UFPI, avaliados em Teresina, Piauí.

\begin{tabular}{lll}
\hline Código dos acessos & Nome comum & Espécie \\
\hline CGC-06 & Murici & Capsicum chinense \\
CGC-07 & Peito-de-moça & Capsicum chinense \\
CGC-11 & Peito-de-moça & Capsicum annuum var. glabriusculum \\
CGC-23 & Olho de peixe & Capsicum chinense \\
CGC-24 & Bredo de moça & Não identificado \\
CGC-26 & Desconhecido & Capsicum baccatum var. pendulum \\
CGC-36 & Pimenta-de-mesa & Capsicum annuum var. glabriusculum \\
CGC-40 & Mexicana longa & Capsicum annuum var.annuum \\
CGC-59 & Desconhecido & Capsicum annuum var. glabriusculum \\
CGC-67 & Desconhecido & Capsicum annuum var. glabriusculum \\
\hline
\end{tabular}


No mês de setembro de 2007, as sementes dos acessos foram semeadas em copos de plástico descartáveis de $125 \mathrm{~mL}$, contendo substrato Plantmax $^{\circledR}$. As mudas com seis folhas definitivas, em média, foram transplantadas para vasos plásticos de 4,5 litros que continham como substrato uma parte de terra vegetal e uma parte de humus de minhoca, com a seguinte formulação: $11,12 \mathrm{~g} \mathrm{~kg}^{-1}$ de $\mathrm{N} ; 5,35 \mathrm{~g}$ $\mathrm{kg}^{-1}$ de $\mathrm{P}_{2} \mathrm{O} ; 13,06 \mathrm{~g} \mathrm{~kg}^{-1}$ de $\mathrm{K}_{2} \mathrm{O} ; 7,8 \mathrm{~g} \mathrm{~kg}^{-1}$ de Ca; $3,4 \mathrm{~g}$ $\mathrm{kg}^{-1}$ de $\mathrm{Mg} ; 10240 \mathrm{mg} \mathrm{kg}^{-1}$ de Fe; $16 \mathrm{mg} \mathrm{kg}^{-1}$ de $\mathrm{Cu}$; $80 \mathrm{mg} \mathrm{kg}^{-1}$ de $\mathrm{Zn} ; 370 \mathrm{mg} \mathrm{kg}^{-1}$ de Mn e $45,4 \%$ de C. No tutoramento das plantas, utilizou-se uma haste de madeira em cada vaso.

A adubação foliar foi realizada com Ouro verde $\left(3 \mathrm{~g}_{1} \mathrm{~L}^{-1}\right)$, aplicado a cada quinze dias. No controle preventivo de pragas e doenças, como, por exemplo, o oídio do pimentão e o ácaro branco, utilizaram-se produtos recomendados para o gênero, conforme as orientações dos rótulos. A irrigação foi manual, utilizando-se um regador.

$\mathrm{Na}$ caracterização morfoagronômica dos acessos, levando-se em conta o potencial ornamental, tomou-se como base os descritores estabelecidos pelo Internacional Plant Genetic Resources Institute para o gênero Capsicum (IPGRI, 1995), atualmente Bioversity International, e os padrões de qualidade estabelecidos pelo Instituto Brasileiro de Floricultura (IBRAFLOR, 2011), quanto aos critérios de classificação para pimentas ornamentais no Brasil relacionados a seguir: forma da folha, hábito de crescimento da planta, antocianina no nó da planta, posição da flor, cor da corola, cor do fruto no estado intermediário e maduro, forma do fruto, forma do ápice do fruto, textura da epiderme do fruto, comprimento do fruto, comprimento do pedicelo, persistência do fruto maduro e altura da planta.

Para os caracteres morfoagronômicos qualitativos relacionados à folha, os dados foram obtidos a partir da moda das observações tomadas em dez folhas por planta, totalizando cento e vinte folhas por acesso; nos qualitativos relacionados ao fruto, observaram-se três frutos por planta, totalizando 36 por acesso; e, nos quantitativos relacionados aos frutos, foram avaliados cinco frutos por planta e 60 por acesso. $\mathrm{O}$ descritor persistência do fruto maduro foi avaliado identificando-se o fruto com uma fita, anotando-se a data de início e fim em que o fruto persistia maduro na planta.

$\mathrm{Na}$ avaliação das qualidades estéticas dos acessos, escolheu-se um exemplar de cada um deles, que apresentasse todos os descritores elencados acima, em boas condições para serem observados. Esses exemplares foram então avaliados com base nos descritores morfoagronômicos referenciados por RUFINO \& PENTEADO (2006), como os mais relevantes para caracterização ornamental em pimentas, que foram: forma da folha, hábito de crescimento da planta, antocianina no nó da planta (observação a olho nu), posição da flor, cor da corola, cor do fruto no estado intermediário e maduro, forma do fruto, forma do ápice do fruto, textura da epiderme do fruto, comprimento do fruto, comprimento do pedicelo, persistência do fruto maduro, altura da planta, número de folhas e número de frutos por plantas.

Os dados dos descritores quantitativos foram submetidos à análise de variância e comparação de média pelo teste de Tukey $(\mathrm{P}<0,05)$, com o auxílio dos recursos computacionais do programa GENES (CRUZ, 2007).

\section{RESULTADOS E DISCUSSÃO}

Na caracterização morfoagronômica, para o descritor forma das folhas, os acessos CGC-06, CGC-07, CGC-24 e CGC-26 apresentaram folhas deltoides; CGC-11, CGC-36 e CGC-59, folhas lanceoladas; e CGC-23, CGC-67 e CGC-40, folhas ovais. Em relação ao hábito de crescimento, os acessos CGC-06, CGC-07, CGC-23, CGC-24, CGC-26 e CGC-40 apresentaram hábito ereto; BGC-36, CGC67 e CGC-59, intermediário; e CGC-11, prostrado. Este descritor é importante no que diz respeito ao manejo da cultura, pois uma planta muito alta, com copa pequena, pode necessitar de tutoramento. Plantas prostradas apresentam a desvantagem de dificultarem o manejo (capinas, enxadas rotativas, pulverizações, entre outros).

Quanto à presença de antocianina no nó da planta, observou-se cor roxa para CGC-06, CGC23, CGC-36 e CGC-67 e cor roxa com tonalidades variando de claro a escuro para CGC-07, CGC-11, CGC-24, CGC-26, CGC-40 e CGC-59. SILVA et al. (2011) relatam que os descritores forma da folha e hábito de crescimento, juntamente com o formato e coloração dos frutos, são bastante significativos no comércio de pimenteiras ornamentais, uma vez que influenciam na harmonia da copa e do vaso, chamando a atenção do consumidor.

Com relação à posição da flor, verificouse que todos os acessos avaliados apresentaram flor ereta. RIBEIRO (2012) afirma que a posição ereta da flor é uma das primeiras características observadas por profissionais do ramo da floricultura na escolha de pimenteiras com potencial ornamental, em função de esta posição deixar as flores em destaque no arranjo floral. 
Para a cor da corola, os acessos CGC-07, CGC-11, CGC-26, CGC-36, CGC-40 e CGC-67 apresentaram corola branca; em CGC-06, CGC-23 e CGC-24, foi observada corola amarela esverdeada e, em CGC-59, corola roxa com base branca. As flores de pimenta, apesar do tamanho reduzido são interessantes para ornamentação, apresentando colorido atraente e posição ereta, que permitem melhor visualização.

Os frutos apresentaram uma grande variabilidade de cores no decorrer do seu desenvolvimento, porém o descritor cor do fruto no estádio imaturo, conforme proposto pelo IPGRI (1995), contempla apenas a fase anterior à maturação. O acesso CGC-23 foi o único que apresentou cor verde no estádio imaturo, os demais apresentaram coloração alaranjada. A cor predominante dos frutos maduros foi vermelha ( $80 \%$ dos acessos), sendo que CGC-11 e CGC-23 apresentaram, respectivamente, cores vermelho claro e laranja pálido.

Para o formato dos frutos, observou-se a forma triangular em quatro acessos (CGC-07, CGC11, CGC-36, CGC-67), alongado em dois (CGC-40, CGC-59), acampanulado em dois (CGC-24, CGC26) e redondo em dois (CGC-06, CGC-23). Segundo CARVALHO et al. (2006), no mercado de plantas de pimentas ornamentais, os descritores cor da corola, cor e formato dos frutos são de grande importância, em função de promoverem contraste com as folhas da planta, expressando suavidade ou agressividade ao arranjo ornamental.

Considerando a forma do ápice no fruto, verificaram-se frutos sem ápice para CGC-06, CGC23, CGC-36 e CGC 67, com ápice afundado para CGC-24, afundado e pontudo para CGC-26 e CGC-07 e pontudo para CGC-59, CGC-40 e CGC-11. Quanto à textura da epiderme dos frutos, os acessos CGC06, CGC-07, CGC-11, CGC-23, CGC-24, CGC-36, CGC-59 e CGC-67 apresentaram textura lisa. Os frutos do CGC-26 apresentaram textura rugosa e do CGC-40, semi-rugosa. De acordo com RIBEIRO (2012), o ápice dos frutos, aliado a sua textura, são de grande relevância na escolha de um arranjo ornamental de pimenta pelo consumidor, sendo que as sem ápice ou com ápice pontudo, e de textura lisa são as mais apreciadas.

Quanto aos descritores quantitativos (Tabela 2), observou-se que o maior comprimento do fruto $(9,65 \mathrm{~cm})$ foi apresentado pelo acesso CGC40 (Capsicum annuum var. annuum), conhecido popularmente como "mexicana longa". Segundo BARBIERILL et al. (2010), Capsicum annuum var. annuum, além de ser domesticada, é a variedade mais cultivada e a mais selecionada pelo homem, justificando, portanto, os maiores valores para comprimento de fruto.

Já os acessos CGC-06, CGC-23 e CGC-36, conhecidos popularmente como pimenta "Murici", "Olho-de-peixe" e "Pimenta-de-mesa", exibiram frutos pequenos $(1,45 \mathrm{~cm} ; 0,96 \mathrm{~cm}$ e $1,33 \mathrm{~cm})$, que são adequados para uso ornamental, como, por exemplo, conservas ornamentais. BUTTOW et al. (2010) indicaram que, quanto menor o tamanho do fruto, maior será a quantidade de frutos produzida por uma pimenteira. Já o comprimento do pedicelo, que variou de 1,65cm (CGC-07) a 3,39cm (CGC-26), é uma característica interessante para a ornamentação, pois os frutos com maior comprimento de pedicelo têm mais destaque em relação às folhas, sendo interessante para plantas cultivadas em vaso e arranjos florais.

Tabela 2 - Médias ${ }^{1}$ dos dez acessos de Capsicum spp. para os descritores comprimento do fruto (CF), comprimento do pedicelo (CP) e persistência do fruto maduro (PFM) e altura da planta (AP), avaliados em Teresina, PI, 2008.

\begin{tabular}{|c|c|c|c|c|}
\hline Acessos & Comprimento do fruto $(\mathrm{cm})$ & Comprimento do pedicelo $(\mathrm{cm})$ & Persistência do fruto maduro (dias) & Altura da planta $(\mathrm{cm})$ \\
\hline BAGC 06 & $1,45 \mathrm{de}$ & $2,26 b$ & $49,08 \mathrm{ab}$ & $59,75 b$ \\
\hline BAGC 07 & $2,28 \mathrm{bc}$ & $1,65 \mathrm{c}$ & $27,67 b$ & $42,17 \mathrm{c}$ \\
\hline BAGC 11 & $2,52 b$ & $1,97 b c$ & $35,00 \mathrm{ab}$ & $19,75 d$ \\
\hline BAGC 23 & $0,96 \mathrm{e}$ & $2,01 \mathrm{bc}$ & $44,08 \mathrm{ab}$ & $61,28 b$ \\
\hline BAGC 24 & $2,56 \mathrm{~b}$ & $2,13 b c$ & $48,33 \mathrm{ab}$ & $97,08 \mathrm{a}$ \\
\hline BAGC 26 & $2,69 b$ & $3,39 a$ & $47,67 \mathrm{ab}$ & $63,83 b$ \\
\hline BAGC 36 & $1,33 \mathrm{de}$ & $1,83 b c$ & $58,83 \mathrm{a}$ & $26,25 \mathrm{~cd}$ \\
\hline BAGC 40 & $9,65^{\mathrm{a}}$ & $2,93 \mathrm{a}$ & $39,36 \mathrm{ab}$ & $70,31 \mathrm{~b}$ \\
\hline BAGC 59 & $1,73 \mathrm{~cd}$ & $2,02 \mathrm{bc}$ & $54,50 \mathrm{ab}$ & $26,25 \mathrm{~cd}$ \\
\hline BAGC 67 & $1,62 d$ & $1,80 \mathrm{bc}$ & $61,67 \mathrm{a}$ & $31,50 \mathrm{~cd}$ \\
\hline Média geral & 2,68 & 2,19 & 46,62 & 49,82 \\
\hline $\mathrm{CV}(\%)$ & 7,35 & 8,29 & 22,61 & 11,17 \\
\hline
\end{tabular}

${ }^{1}$ Média seguidas pela mesma letra, nas colunas, não diferem pelo teste de Tukey $(\mathrm{P}<0,05)$. 
A persistência do fruto maduro, cujas médias variaram de 61,67dias (CGC-67) a 27,67dias (CGC-07), é uma característica importante para a ornamentação, pois o fruto é um dos grandes atrativos ao consumidor, sendo interessante sua maior permanência na planta. O acesso CGC-24 apresentou as plantas mais altas $(97,08 \mathrm{~cm})$, enquanto CGC-11, CGC-36, CGC-59 e CGC-67 foram as mais baixas $(19,75 \mathrm{~cm} ; 26,25 \mathrm{~cm} ; 26,25 \mathrm{~cm}$ e $31,50 \mathrm{~cm}$, respectivamente). RUFINO \& PENTEADO (2006) relatam que as plantas de até $45 \mathrm{~cm}$ de estatura são as mais adequadas para o cultivo em vaso. Já NEITZKE (2008) cita que plantas de pimenta de pequeno porte também podem ser cultivadas em jardim, e que as de porte mais alto são recomendadas para o cultivo em jardins funcionais, como os de temperos, os de plantas medicinais e os aromáticos. Segundo BENTO et al. (2007), para se determinar os tratos culturais de uma lavoura de pimenta ou pimentão, é necessário saber, de antemão, a altura da planta. Essa informação é fundamental na determinação da necessidade de tutoramento, tipo de tutor, quantidade de mão de obra e gasto com defensivos.

Quanto ao potencial ornamental dos acessos, com base nas qualidades estéticas, verificouse que nenhum deles apresentou ao mesmo tempo todas as características desejáveis para a ornamentação. Contudo, dentre os dez acessos avaliados, sete foram considerados com potencial ornamental: CGC-06 (C. chinense), CGC-07 (C. chinense), CGC-11 (C. annuum var. glabriusculum), CGC-23 (C. chinense), CGC-36 (C. annuum var. glabriusculum), CGC59 (C. annuum var. glabriusculum) e CGC-67 (C. annuum var. glabriusculum)

A espécie Capsicum annuum var. glabriusculum (CGC-11) destacou-se entre as demais por apresentar características morfologicamente mais adequadas à ornamentação. Corroborando este resultado, SUDRÉ et al. (2006) relatam que as plantas $\boldsymbol{C}$. annuum são muito interessantes para cultivo em vaso, por apresentarem frutos de coloração vermelha quando maduros, com posição ereta que contrastam com a folhagem. Segundo estes autores, as plantas $\boldsymbol{C}$. Chinense, embora possuam porte relativamente baixo, não são muito promissoras para o uso ornamental, pois possuem frutos pendentes que ficam muitas vezes escondidos sob a folhagem, dificultando sua visualização. Porém, sugerem que as plantas desta espécie podem ser cruzadas com outros genótipos para incorporar caracteres que aumentem seu valor estético, como a posição ereta dos frutos e a presença de um maior número de cores durante o processo de maturação do fruto. De acordo ainda com os autores citados, as pimenteiras desta espécie podem ser usadas como complemento de arranjos florais em função de seus frutos serem pequenos, atraentes e de boa durabilidade.

\section{CONCLUSÃO}

Os acessos avaliados possuem potencial ornamental, com destaque para CGC-11, Capsicum annuum var. gabriusculum (Peito de moça), com estética harmoniosa por apresentar flores eretas, as quais são de fácil percepção; frutos eretos e vistosos e folhas de formato lanceolado.

\section{REFERÊNCIAS}

BENTO, C.S. et al. Descritores qualitativos e multicategóricos na estimativa da variabilidade fenotípica entre acessos de pimentas. Scientia Agraria, Curitiba, v.8, n.2, p.149-156, 2007. Disponível em: <http://ojs.c3sl.ufpr.br/ojs2/index.php/agraria/ article/view/8379/6661>. Acesso em: 14 jun. 2013.

BÜTTOW, M.V. et al. Diversidade genética entre acessos de pimentas e pimentões da Embrapa Clima Temperado. Ciência Rural, Santa Maria, v.40, n.6, p.1264-1269, jun. 2010. Disponível em: 〈http://www.scielo.br/pdf/cr/v40n6/a617cr2589.pdf>. Acesso em: 15 jun. 2013.

CARVAlHO, S.I.C. et al. Pimentas do gênero Capsicum no Brasil. Brasília: Embrapa Hortaliças, 2006. 27p. (Documentos, 94).

COSTA, F.R. et al. Genetic diversity among Capsicum accessions using RAPD markers. Crop Breeding and Applied Biotechnology, Viçosa, v.6, n.1, p.18-23, 2006. Disponível em: <http://www.sbmp.org.br/cbab/siscbab/uploads/bd6ba09c-4aa3b62a.pdf>. Acesso em: 08 mar. 2013.

CRUZ, C.D. Genes: aplicativo computacional em genética e estatística. Viçosa: UFV, 2007. (Versão 2007.0.0).

DOMENICO, C.I. et al. Caracterização agronômica e pungência em pimento de cheiro. Horticultura Brasileira, v.30, p.466-472, 2012. Disponível em: <http://www.scielo.br/pdf/hb/v30n3/18. pdf>. Acesso em: 03 jun. 2013.

INSTITUTO BRASILEIRO DE FLORICULTURA (IBRAFLOR). Disponível em: <http://www.ibraflor.com/ns_mer_interno.php>. Acesso em: 20 jan. 2013.

INTERNACIONAL PLANT GENETIC RESOURCES INSTITUTE (IPGRI). Descriptores para Capsicum (Capsicum spp). Roma, 1995. 51p.

JUNQUEIRA, A.H.; PEETZ, M.S. Mercado interno para os produtos da floricultura brasileira: características, tendências e importância socioeconômica recente. Revista Brasileira de Horticultura Ornamental, São Paulo, v.14, n.1, p.3752, 2011. Disponível em: <http://www.hortica.com.br/artigos/ HORTORNAMENTALMercado.pdf>. Acesso em: 20 ago. 2013.

NEITZKE R.S. et al. Divergência genética entre variedades locais de Capsicum baccatum utilizando caracteres multicategóricos. 
Magistra, Cruz das Almas, v.20, n.3, p.249-255, 2008. Disponível em: <http://www.magistra.ufrb.edu.br/publica/20.3\%20PDF/06 Divergencia_genetica_entre_variedades_locais.pdf $>$. Acesso em: 15 mar. 2012.

NEITZKE, R.S. et al. Dissimilaridade genética entre acessos de pimenta com potencial ornamental. Horticultura Brasileira, Vitória da Conquista v. 28, p. 47-53, 2010. Disponível em: <http:// www.scielo.br/pdf/hb/v28n1/a09v28n1.pdf>. Acesso em: 14 jun. 2013.

RIBEIRO, W.S. Avaliação de substratos e poda na produção de pimenteira ornamental. 2012. 92f. Dissertação (Mestrado em Agronomia) - Curso de Pós-graduação em Fitotecnia, Universidade Federal de Viçosa, MG.

RUFINO, J.L.S.; PENTEADO, D.C.S. Importância econômica, perspectiva e potencialidades do mercado para pimenta. Informe Agropecuário, Brasília, v.27, p.07-15, 2006. Disponível em: $<$ http://www.scielo.br/scielo.php?script=sci_nlinks\&ref=000130 \&pid=S0034737X201200040000900223\&lng=en>. Acesso em: 07 set. 2006

SILVA, J.S.C. et al. Emergência e crescimento inicial de plântulas de pimenta ornamental e celosia em substrato à base de composto de Iodo de curtume. Ciência Rural, Santa Maria, v.41, n.3, p.412417, 2011. Disponível em: <http://dx.doi.org/10.1590/S010384782011000300008>. Acesso em: 07 set. 2012. doi: 10.1590/ S0103-84782011000300008.

SUDRÉ, C.P. et al. Variáveis multicategóricas na determinação da divergência genética entre acessos de pimenta e pimentão. Horticultura Brasileira, Vitória da Conquista, v.24, p.88-93, 2006. Disponível em: <http://www.scielo.br/pdf/hb/v24n1/ a18v24n1.pdf $>$. Acesso em: 12 jul. 2013.

VASCONCELOS, C.S. et al. Determinação da dissimilaridade genética entre acessos de Capsicum chinense com base em características de flores. Revista Ceres, Viçosa, v.59, n.4, p.493498, 2012. Disponível em: <http://dx.doi.org/10.1590/S0034737X2012000400009>. Acesso em: 01 ago. 2013. doi: 10.1590/ S0034-737X2012000400009.

ZENI, A.L.; BOSIO, F. O uso de plantas medicinais em uma comunidade rural de Mata Atlântica - Nova Rússia, SC. Neotropical Biology and Conservation, São Leopoldo, v.6, n.1, p.55-63, 2011. Disponível em: <http://revistas.unisinos.br/index. php/neotropical/article/view/997/210>. Acesso em: 01 ago. 2013. doi: $10.4013 /$ nbc.2011.61.07. 